\title{
PROCESSOS DE TROCA CATIÔNICA PARA OBTENÇÃO DE Na-BENTONITA A PARTIR DE UMA Mg-BENTONITA NATURAL DO MARANHÃO
}

\author{
M. V. C. SILVA ${ }^{1}$, J. L. FERREIRA ${ }^{2}$, S. P. A. PAZ ${ }^{3}$, R. S. ANGÉLICA ${ }^{4}$ e R. F. NEVES ${ }^{1}$ \\ ${ }^{1}$ Universidade Federal do Pará, Faculdade de Engenharia Química \\ ${ }^{2}$ Universidade Federal do Pará, Programa de Pós Graduação em Engenharia Química \\ ${ }^{3}$ Universidade Federal do Pará, Faculdade de Engenharia de Materiais \\ ${ }^{4}$ Universidade Federal do Pará, Faculdade de Geologia \\ E-mail para contato: marcus.ufpa@yahoo.com.br
}

\begin{abstract}
RESUMO - As bentonitas sódicas possuem diversas aplicações industriais. No entanto, esses materiais são raros e o Brasil, por exemplo, não dispõe desse tipo catiônico. Uma Mg-bentonita, descoberta no município de Formosa da Serra Negra (Sul do Maranhão), referenciada Formosa, foi submetida a dois tratamentos com solução de carbonato de sódio, visando sua transformação em sódica pelo processo de troca catiônica. A diferença principal dos dois processos foi a introdução da etapa de extrusão em um deles. $\mathrm{O}$ material de partida e os produtos foram caracterizados por DRX, FRX e Análise do Grau de Inchamento. O espaçamento basal da bentonita diminuiu de 15,4 para $12,5 \AA$ em ambos os tratamentos. O grau de inchamento aumentou de 6 para $13 \mathrm{~mL}$ (no processo sem extrusão) e de 6 para $29 \mathrm{~mL}$ (no processo com extrusão). Esses resultados confirmaram a obtenção de Na-bentonita a partir da Mg-bentonita Formosa, o que aumenta a possibilidade de seu uso futuro na indústria.
\end{abstract}

\section{INTRODUÇÃO}

Bentonita é uma argila plástica constituída essencialmente pelo argilomineral montmorillonita, que é o principal representante do grupo esmectita. Em menor quantidade, apresenta como minerais acessórios: quartzo, feldspatos, hematita, cristobalita, caulinita, illita, entre outros (Grim, 1968). Uma grande característica dos argilominerais esmectíticos é a presença de um elevado grau de substituição isomórfica dentro da estrutura cristalográfica, o que origina um excesso de carga negativa que são compensadas por cátions interlamelares (Lagaly, 1981). Esses materiais podem se apresentar na forma monocatiônica ou policatiônica, dependendo de qual cátion é mais predominante em sua constituição interplanar (Zandonadi, 1972; Santos, 1992; Amorim et al., 2006).

As argilas bentoníticas estão incluídas na classe dos minerais de maior interesse industrial, possuindo um largo campo de aplicação. As bentonitas sódicas, que possuem elevada capacidade de expansão e hidratação, são as mais adequadas aos usos mais nobres dessa argila e são usadas, principalmente, como fluidos de perfuração de poços de petróleo, como aglomerante em areias de moldagem para fundição e na pelotização de minério de ferro (Lagaly e Ziesmer, 2003; Coelho et al., 2007 a,b). 
As bentonitas brasileiras, normalmente cálcicas e/ou magnesianas, precisam passar por um processo de troca catiônica para serem transformadas em sódicas. Esse processo é comumente denominado de ativação sódica e consiste na troca dos $\mathrm{Ca}^{2+} \mathrm{e} / \mathrm{ou} \mathrm{Mg}^{2+}$ originais da argila pelo $\mathrm{Na}^{+}$em solução, ou mesmo na forma sólida, sendo a barrilha a fonte mais comumente utilizada (Teixeira-Neto e Teixeira-Neto, 2009). Essa ativação sódica é uma reação química de dupla troca reversível (Santos, 1992).

As bentonitas sódicas apresentam um elevado índice de inchamento, que está associado à hidratação dos cátions $\mathrm{Na}^{+}$, que provoca um acúmulo de moléculas de água no espaço interlamelar da montmorillonita.

Uma explicação para que a capacidade de expansão da bentonita sódica seja muito maior do que as formas cálcica e/ou magnesiana está no alto grau de hidratação do $\mathrm{Na}^{+} \mathrm{em}$ relação ao $\mathrm{Ca}^{2+}$ e ao $\mathrm{Mg}^{2+}$. Além disso, quando as lamelas têm suas cargas compensadas pelo íon sódio, de menor valência, apresentam-se mais afastadas devido à menor energia de interação, permitindo assim a penetração de uma maior quantidade de moléculas de água no espaço entre as lamelas (Teixeira-Neto e Teixeira-Neto, 2009).

No Brasil, as argilas bentoníticas mais utilizadas em diversas aplicações industriais são provenientes principalmente do município de Boa Vista, no estado da Paraíba. No entanto, a exploração dos jazimentos de Boa Vista por dezenas de anos levou ao esgotamento das variedades de boa qualidade, levando a uma dependência maior de bentonitas importadas (Amorim et al., 2004; Menezes et al., 2008). Todo esse panorama evidencia a importância da descoberta de novos jazimentos de bentonitas no Brasil. Assim sendo, o Grupo de Mineralogia e Geoquímica Aplicada (GMGA) da UFPA vem desenvolvendo trabalhos de prospecção, caracterização, modificação e aplicação dessas novas ocorrências.

Recentemente, duas novas ocorrências de bentonitas brasileiras foram descritas, ambas localizadas no estado do Maranhão, são elas: a bentonita Balsas (Moraes et al., 2010) e a bentonita Formosa (Paz et al., 2011; Paz et al., 2012). Dando continuidade às pesquisas do GMGA, objetivou-se nesse trabalho a obtenção de Na-bentonita a partir da Mg-bentonita Formosa pelo processo de troca catiônica com carbonato de sódio.

\section{MATERIAIS E MÉTODOS}

O material utilizado é proveniente de um depósito ainda não lavrado, situado as margens da Rodovia MA 006, município de Formosa da Serra Negra, sul do Maranhão. Esse material apresenta mineralogia a base de montmorillonita e magnitude importante do ponto de vista tecnológico (Paz et al., 2011; Paz et al., 2012).

Uma amostra de Na-bentonita comercial dos Estados Unidos foi utilizada como padrão de referência no desenvolvimento desse trabalho. A Bentonita em questão é proveniente do estado de Wyoming (EUA), e é referência mundial em usos em fluidos de perfuração de poços de petróleo.

A bentonita Formosa (referenciando o local de origem) foi britada, moída, classificada abaixo de 0,15 mm (100 mesh) em peneiramento manual e homogeneizada. A amostra de 
referência (Wyoming) foi pulverizada em almofariz e também foi classificada abaixo de 0,15 mm em peneiramento manual.

\subsection{Processos de ativação sódica}

Processo 1: uma quantidade de $100 \mathrm{~g}$ da bentonita Formosa foi tratada com solução concentrada de carbonato de sódio $(0,2 \mathrm{~g} / \mathrm{mL})$ na proporção de $100 \mathrm{meq} / 100 \mathrm{~g}$ de argila. A mistura foi homogeneizada manualmente e, em seguida, envelhecida por 7 dias em câmara úmida a $100 \%$ de umidade relativa. Diariamente, o material era mexido por 3 minutos. Após os sete dias, o material foi seco a $70{ }^{\circ} \mathrm{C}$, pulverizado em almofariz, classificado abaixo de 0,15 mm (100 mesh) em peneiramento manual e recebeu a nomenclatura Formosa-A1 (Bentonita Formosa ativada pelo processo 1).

Processo 2: foi realizada uma metodologia que mais se aproxima da utilizada industrialmente. Uma quantidade de $500 \mathrm{~g}$ da bentonita Formosa foi tratada com solução concentrada de carbonato de sódio $(0,2 \mathrm{~g} / \mathrm{mL})$ na proporção de $100 \mathrm{meq} / 100 \mathrm{~g}$ de argila. A mistura foi homogeneizada manualmente e, em seguida, foi introduzida em um pequeno equipamento que realiza a mesma função de uma extrusora. Os bastões formados foram curados por um dia em câmara úmida a $100 \%$ de umidade relativa. Após o tempo de cura, os bastões foram expostos à luz solar para secagem durante 5 horas. Os bastões foram desagregados em almofariz e o pó formado foi classificado abaixo de 0,15 $\mathrm{mm}$ (100 mesh) em peneiramento manual. O material recebeu a nomenclatura Formosa-A2 (Bentonita Formosa ativada pelo processo 2 ).

\subsection{Técnicas de caracterização}

As amostras naturais e os materiais obtidos após os tratamentos sódicos foram caracterizados por Difração de Raios-X, Fluorescência de Raios-X e Análise do grau de inchamento.

Difração de Raios-X: as análises foram realizadas em um Difratômetro de Raios-X, modelo X'PERT PRO MPD (PW 3040/60), da PANalytical, com goniômetro PW3050/60 ( $\theta$ / $\theta$ ), tubo de Raios-X cerâmico e anodo de $\mathrm{Cu}(\mathrm{K} \alpha 1=1,540598 \AA$ A), modelo PW3373/00 com foco fino $(2200 \mathrm{~W} / 60 \mathrm{kV})$, e filtro $\mathrm{K} \beta$ de Níquel. As condições instrumentais utilizadas foram as seguintes: varredura de 3 a $75^{\circ}$ em $2 \theta$, voltagem de $40 \mathrm{kV}$, corrente de $30 \mathrm{~mA}$, tamanho do passo de $0,02^{\circ}$ em $2 \theta$, tempo/passo de $81 \mathrm{~s}$, fenda divergente de $1 / 4^{\circ}$ e antiespalhamento de $1 / 2^{\circ}$, máscara de $10 \mathrm{~mm}$ e movimentação circular da amostra com frequência de 1 rotação/s. A aquisição de dados foi feita com o software X'Pert Data Collector, e o tratamento dos dados com o software X'Pert HighScore.

Fluorescência de Raios-X: as análises foram realizadas em um Espectrômetro de Fluorescência de Raios-X, modelo Axios Minerals, da PANalytical, com tubo de raios-X cerâmico e anodo de Ródio, com potência de $2,4 \mathrm{~kW}$. As determinações foram feitas no programa IQ+ Semiquant. A aquisição dos dados foi feita com o software SuperQ Manager, e o tratamento dos mesmos com o software IQ+. A preparação das amostras para as análises foram realizadas a partir de pastilhas fundidas, com a utilização de $1 \mathrm{~g}$ de amostra para $6 \mathrm{~g}$ de Tetraborato de Lítio, que é o fundente. 
Análise do grau de inchamento: Em uma proveta contendo $100 \mathrm{~mL}$ de água destilada foram introduzidos vagarosamente aproximadamente $2 \mathrm{~g}$ da amostra durante duas horas. $\mathrm{O}$ material permaneceu em repouso durante 24 horas. $\mathrm{O}$ valor do inchamento foi obtido através da leitura feita na graduação da proveta, expresso em $\mathrm{mL}$, após 24 horas do término da adição da bentonita. Esses procedimentos seguiram os passos da norma NBR 8101 (ABNT).

\section{RESULTADOS E DISCUSSÃO}

As composições químicas das amostras naturais e dos materiais obtidos após os tratamentos sódicos estão apresentadas na Tabela 1. Nota-se que a Formosa possui como componentes principais $\mathrm{SiO}_{2}$ e $\mathrm{Al}_{2} \mathrm{O}_{3}$. Apresenta alto teor de $\mathrm{Fe}_{2} \mathrm{O}_{3}, 14,92 \%$, característica das argilas esmectíticas brasileiras. Todos os valores dos constituintes presentes estão bem próximos aos encontrados por Paz et al. (2011). Como esperado, após o tratamento sódico, as amostras Formosa-A1 e Formosa-A1 apresentaram teores relevantes de $\mathrm{Na}_{2} \mathrm{O}: 3,30 \%$ e 3,32 $\%$, respectivamente. As amostras obtidas após os tratamentos apresentaram valores de $\mathrm{Na}_{2} \mathrm{O}$ maiores que o da própria bentonita Wyoming, que é naturalmente sódica. A bentonita norteamericana também apresenta como componentes principais $\mathrm{SiO}_{2}$ e $\mathrm{Al}_{2} \mathrm{O}_{3}$.

Tabela 1 - Composição química das amostras naturais e modificadas

\begin{tabular}{ccccc}
\hline \multirow{2}{*}{$\begin{array}{c}\text { Constituintes } \\
(\%)\end{array}$} & Formosa & Formosa-A1 & Formosa-A2 & Wyoming \\
\cline { 2 - 5 } & 47,39 & 46,23 & 46,15 & 63,77 \\
$\mathbf{S i O}_{\mathbf{2}}$ & 17,20 & 16,76 & 16,42 & 18,53 \\
$\mathbf{A l}_{\mathbf{2}} \mathbf{O}_{\mathbf{3}}$ & 14,92 & 14,08 & 14,07 & 3,89 \\
$\mathbf{F e}_{\mathbf{2}} \mathbf{O}_{\mathbf{3}}$ & 3,58 & 3,39 & 3,31 & 2,46 \\
$\mathbf{M g O}$ & 0,26 & 0,30 & 0,28 & 1,50 \\
$\mathbf{C a O}$ & 1,57 & 1,57 & 1,56 & 0,48 \\
$\mathbf{K}_{\mathbf{2}} \mathbf{O}$ & - & $\mathbf{3 , 3 0}$ & $\mathbf{3 , 3 2}$ & $\mathbf{1 , 6 6}$ \\
$\mathbf{N a}_{\mathbf{2}} \mathbf{O}$ & 0,13 & $<0,10$ & $<0,10$ & - \\
$\mathbf{M n O}$ & 1,60 & 1,54 & 1,50 & 0,15 \\
$\mathbf{T i O}_{\mathbf{2}}$ & $<0,10$ & $<0,10$ & $<0,10$ & 0,08 \\
$\mathbf{P}_{\mathbf{2}} \mathbf{O}_{\mathbf{5}}$ & 13,36 & 12,74 & 13,39 & 7,36 \\
$\mathbf{P . F}$. & &
\end{tabular}

P.F. = perda ao fogo determinada com a queima a $1000^{\circ} \mathrm{C}$.

Os difratogramas das amostras naturais e dos materiais obtidos após os tratamentos sódicos estão apresentadas na figura 1. Na Formosa, observa-se que há a presença predominante de esmectita-montmorillonita, a partir da identificação dos três picos principais: em 15,$4 ; 4,47$ e $1,495 \AA$. O primeiro está associado ao plano cristalográfico principal da estrutura do argilomineral, o (001), enquanto o último, o pico (060), é considerado a impressão digital da montmorillonita, pois discrimina as espécies di ou trioctaédricas (Moore e Reynolds, 1989). A amostra também apresenta traços de K-feldspato, hematita e caulinita. Observa-se que com o tratamento sódico, houve uma diminuição do espaçamento basal 
(d001), passando de 15,4 $\AA$ na Formosa para 12,5 $\AA$ na Formosa-A1 e Formosa-A2, valores aproximadamente iguais ao da bentonita Wyoming (12 ̊), naturalmente sódica. Essa alteração no espaçamento basal confirma a saída dos cátions $\mathrm{Mg}^{2+}$ e possivelmente $\mathrm{Ca}^{2+}$ (ambos de maior raio iônico) da bentonita Formosa, substituídos por $\mathrm{Na}^{+}$(de menor raio iônico), mostrando que os dois processos empregados foram realizados com sucesso. Esses resultados estão de acordo com os dados obtidos por outros autores. Silva et al. (2007) conseguiram uma diminuição do espaçamento basal da bentonita Chocolate (brasileira) de 15 $\AA$ para $12,6 \AA$, após tratamento sódico com $\mathrm{Na}_{2} \mathrm{CO}_{3}$. Líbano et al. (2012) conseguiram uma diminuição do espaçamento basal de outra bentonita brasileira de $15,13 \AA$ para $12,1 \AA$, após tratamento sódico com $\mathrm{NaCl}$.

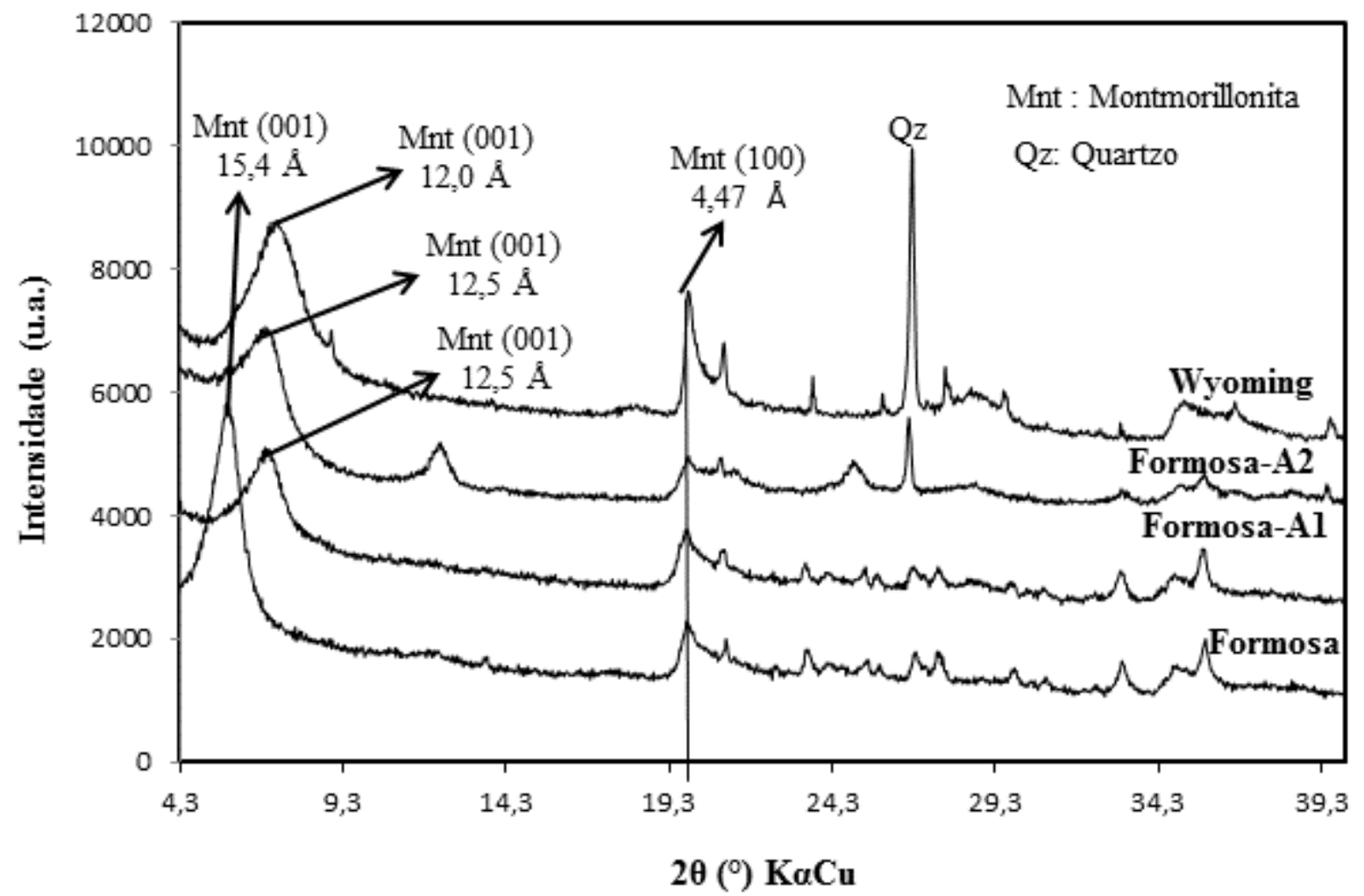

Figura 1 - Difratogramas das amostras naturais e dos materiais obtidos após os tratamentos sódicos

Os valores de inchamento das amostras naturais e dos materiais obtidos após os tratamentos sódicos estão apresentadas na figura 2. Observa-se que com o tratamento sódico, o valor do inchamento passou de $6 \mathrm{~mL}$ na Formosa para $13 \mathrm{~mL}$ na Formosa-A1 e $29 \mathrm{~mL}$ na Formosa-A2, mostrando que após as amostras serem saturadas com sódio, as moléculas de água se introduziram no espaço interlamelar da argila, provocando sua expansão. A bentonita Wyoming apresentou um valor de inchamento bem maior, $46 \mathrm{~mL}$, por ser naturalmente sódica. Em relação aos resultados de inchamento, o processo 2 (com extrusão) se mostrou mais eficiente, pois houve um aumento de cerca de 5 vezes do valor inicial, possivelmente devido à maior área de contato entre o carbonato de sódio e a argila durante a extrusão. Os dados de inchamento das amostras ativadas no presente trabalho são maiores que os 
encontrados por Aranha et al. (2002), os quais obtiveram valores de $9 \mathrm{~mL}$ para a bentonita Chocolate e $11 \mathrm{~mL}$ para a bentonita CBPM-A, ambas ativadas com $\mathrm{Na}_{2} \mathrm{CO}_{3}$.

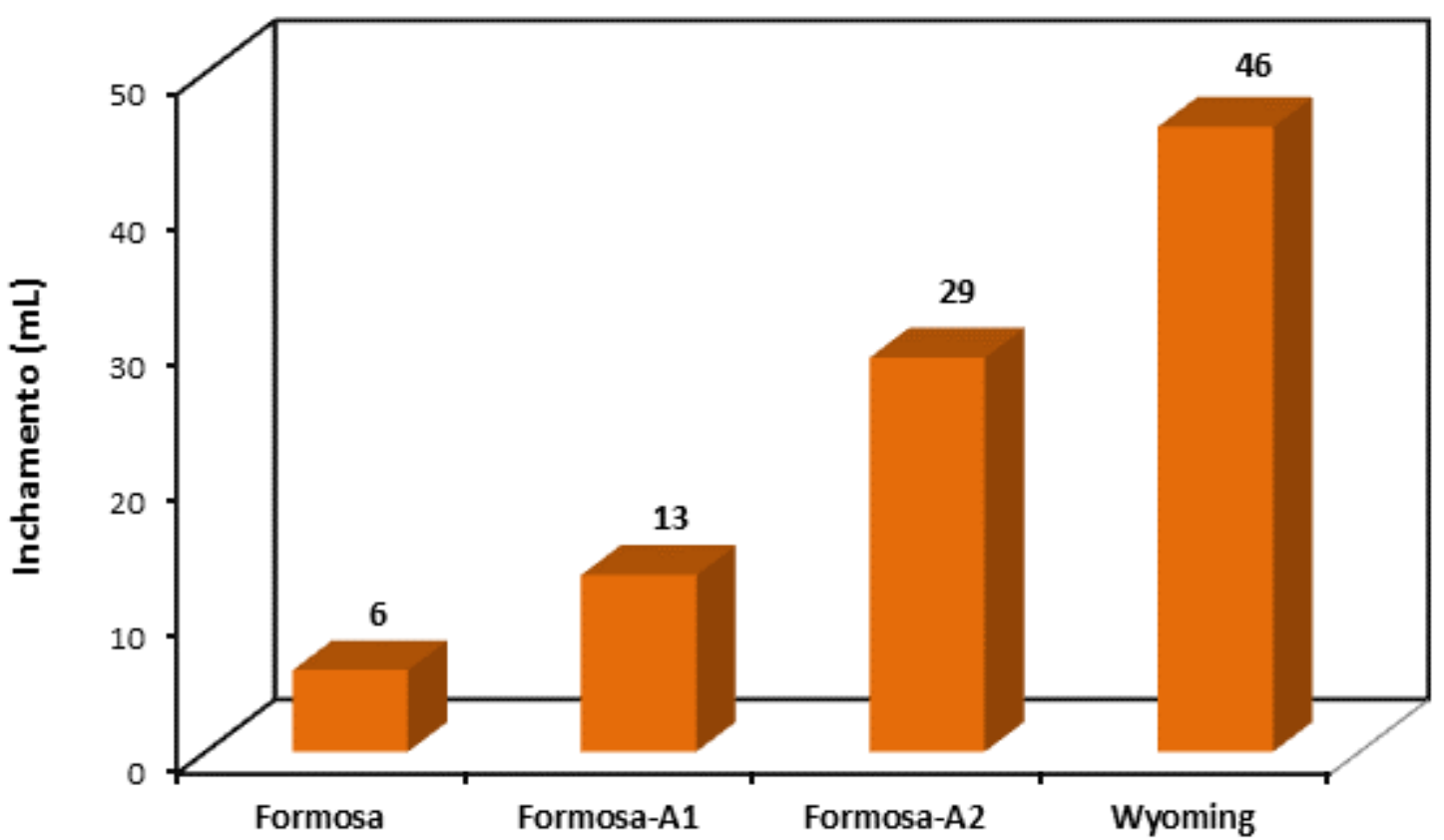

Figura 2 - Valores de inchamento das amostras naturais e dos materiais obtidos após os tratamentos sódicos

\section{CONCLUSÃO}

Os processos de troca catiônica com $\mathrm{Na}_{2} \mathrm{CO}_{3}$ obtiveram bastante êxito e foi possível transformar a Mg-bentonita Formosa em sódica. O processo 2 (com extrusão) resultou em um material com maior grau de inchamento. Esse trabalho trás uma grande contribuição científica no sentido de apresentar uma nova ocorrência de bentonita policatiônica brasileira que pode ser transformada em sódica, que possui grande potencial para uso em diversas aplicações, como por exemplo, em fluidos de perfuração de poços de petróleo, pelotização de minério de ferro e em fundição. Isso é de extrema importância, pois a maioria das reservas de bentonitas do Brasil, que se encontram no estado da Paraíba, já está exaurindo.

\section{REFERENCIAS}

AMORIM, L. V.; GOMES, C. M.; LIRA, H. L.; FRANÇA, K. B.; FERREIRA, H. C. Bentonites from Boa Vista, Brazil: Phisical, Mineralogical and Rheological Properties. Materials Research, v. 7, n.4, p. 583-593, 2004.

AMORIM, L. V.; VIANA, J. D.; FARIAS, K. V.; BARBOSA, M. I. R.; FERREIRA, H. C. Estudo comparativo entre Variedades de argilas bentoníticas de Boa Vista. Revista Matéria, v.11, p. 30-40, 2006. 
ARANHA, I. B.; OLIVEIRA, C. H.; NEUMANN, R.; ALCOVER NETO, A.; LUZ, A. B. Caracterização mineralógica de bentonitas brasileiras. Anais do XIX ENTMME, Recife (PE), 2002.

COElHO, A. C. V.; SANTOS, P. S.; SANTOS, H. S. Argilas Especiais: O que são, caracterização e propriedades. Química Nova, v. 30, n. 1, p. 146-152, 2007a.

COELHO, A. C. V.; SANTOS, P. S.; SANTOS, H. S. Argilas Especiais: argilas quimicamente modificadas - uma revisão. Química Nova, v. 30, n. 5, p. 1282-1294, 2007b.

GRIM, R. E. Clay Mineralogy, 2 ed. New York: McGraw-Hill, 1968.

LAGALY, G. Characterization of clays by organic compounds. Clay Minerals, v. 16, n. 1, p. $1-21,1981$.

LAGALY, G. e ZIESMER, S. Colloid chemistry of Clay minerals: the coagulation of montmorillonite dispersions. Advances in Colloid and Interface Science, v. 100-102, p. 105$128,2003$.

LÍBANO, E. V. D. G.; VISCONTE, L. L. Y.; PACHECO, E. B. A. V. Propriedades Térmicas de Compósitos de Polipropileno e Bentonita Organofílica. Polímeros, v. 22, n. 5, p. 430-435, 2012.

MENEZES, R. R.; MELO, L. R. L.; FONSECA, F. A. S.; FERREIRA, H. S.; MARTINS, A. B.; NEVES, G. A. Caracterização de argilas bentoníticas do Municipio de Sussego, Paraíba, Brasil. Revista Eletrônica de Materiais e Processos, v. 3, n. 2, p. 36-43, 2008.

MOORE, D. M. e REYNOLDS, Jr. R. C. X-ray Diffraction and the Identification of Clay Minerals. Oxford: Oxford University Press, 332 p., 1989.

MORAES, D. S.; ANGÉLICA, R. S.; COSTA, C. E. F.; ROCHA FILHO, G. N.; ZAMIAN, J. R. Mineralogy and chemistry of a new bentonite occurrence in the eastern Amazon region, northern Brazil. Applied Clay Science, v. 48, n. 3, p. 475-480, 2010.

PAZ, S. P. A.; ANGÉlICA, R. S.; NEVES, R. F.; NEUMANN, R.; COSTA, G. M. Ocorrência de uma nova bentonita brasileira nos basaltos intemperizados da formação Mosquito, bacia do Parnaíba, sul do Maranhão. Cerâmica, v. 57, n. 344, p. 444-452, 2011.

PAZ, S. P. A.; ANGÉLICA, R. S.; NEVES, R. F. Mg-Bentonite in the Parnaíba Paleozoic Basin, Northern Brazil. Clay and Clay Minerals, v. 60, n. 3, p. 265-277, 2012.

SANTOS, P. S. Ciência e tecnologia de argilas, vol. 1, 2 ed. São Paulo: Edgar Blücher, 1992.

SILVA, A. A.; VANENZUELA-DIAS, F. R.; MARTINS, G. S. V.; RODRIGUES, M. G. F. Preparação de argilas organofílicas usando diferentes concentrações de sal quaternário de amônio. Cerâmica, v. 53, p. 417-422, 2007.

TEIXEIRA-NETO, E. e TEIXEIRA-NETO, A. M. Modificação química de argilas: Desafios científicos e tecnológicos para obtenção de novos produtos com maior valor agregado. Química Nova, v. 32, n. 3, p. 809-817, 2009.

ZANDONADI, A. R. Estudo tecnológico de argilas montmoriloníticas brasileiras. Tese de Doutorado, Instituto de Química da USP, 1972. 